\title{
Journal of Arabic Literature (Leiden, E. J. Brill, 1970-)
}

関 根 謙 司

1970年以来, オックスフォード大学のバダウィ M. M. Badawi, エディンバラ 大学のカキア P. Cachia, ケンブリッヂ大学のライオンズ M. C. Lyons, グラスゴ 一大学のマトック J. N. Mattock の 4 教授を編者・監修者として年刊で刊行され てきた本誌は，今日まで予定ど拉り，全文英語で計 4 冊を世に問うてきた。イス ラム学, アラブ学の専門誌が多いなかで, 本誌は西欧の学会に拈ける唯一のくア ラブ文学>の専門的な研究・翻訳誌といえよう。そこで本誌の書評を試みる過程 で，今や 200 年を超えんとしている西欧のアラブ文学研究の方法を問い，あわせ てそのく意味〉を考察してみたい。

さて，本誌に揭載された論文，翻訳などを示すと，以下のと扣りである。

[vol. I (1970)]

page

Introduction

M. C. Lyons and P. Cachia; The Effect of Monorhyme on Arabic Poetic

Production

Modern Arabic Poetry I (trans. M. M. Badawi) 14

S. Somekh; $Z a^{\prime} b a l \bar{a} w \bar{\imath} \longrightarrow$ Author, Theme and Technique 24

A. M. K. al-Zubaidi ; The Dīwān School 36

R. Park ; "And heard Greet Argument": An Essay in the Practical Criticism of Arabic Poetry 49

Jacob M. Landau ; Muḥammad Thābit, A Modern Arab Traveller 70

Modern Arabic Poetry II (trans M. A. Khouri and H. Algar) 75

Roger Alleen; Hadith 'Isa Ibn Hisham by Muhammad al-Muwailihī. A

Reconsideration $\quad 88$

A. J. Arberry ; Two Rare Manuscripts 109

Modern Arabic Poetry III (trans. M. A. Khouri and H. Algar) 117 
オリエントXVIII-1 (1975)

P. J.E. Cachia; The Dramatic Monologues of al-Ma'arrī

129

Mounah A. Khouri; Lewis 'Awad : A Forgotten Pioneer of the Free Verse Movement

M. M. Badawi ; The Lamp of Umm Hāshim: the Egyption Intellectua1 between East and West 145

Modern Arabic Poetry IV (trans. H. M. Nahmad)

[vol. II (1971)]

A. F. L. Beeston; The Genesis of the Maqāmāt Genre

F. Klein-Franke; The Ḥamāsa of Abū Tammām (Part 1) 13

A.C.F. Verity ; Two Poems of Abū'l-Alā al-Ma'arrī 37

K. Abu Deeb ; al-Jurjān̄̄'s Classification of Isti ${ }^{\prime} \bar{a} r a \quad 48$

Jabra Ibrahim Jabra; Modern Arabic Literature and the West 76

'In the Ladies' Compartment' by Rashād Rushdī, trans. P. Cachia 92

Modern Arabic Poetry, trans. M. M. Badawi 98

Issa J. Boullata; The Poetic Technique of Badr Shākir al-Sayyāb 104

R. C. Ostle ; Khalīl Muțrān: The Precursor of Lyrical Poetry in Modern Arabic

al-Hilāl : A critical analysis of a poem by Shawqī 127

D. Semah; Muhammad Mandūr and 'New Poetry' 143

M. M. Badawi ; Islam in Modern Egyptian Literature 154

P. Cachia; Themes Related to Christianity and Judaism in Modern Egyptian

Drama and Fiction

Review

The Life and Works of Jāhịiz, translations by Charles Pellat (A. F. L.

Beeston)

[vol. III (1972)]

J. T. Monroe; Oral Composition in Pre-Islamic Poetry

G. H. A. Juynboll ; Ismā‘̄il Aḥmad Adham (1911 1940), the Atheist 54

M. Abdel-Hai ; Shelley and the Arabs: An Essay in Comparative Literature 72

$\begin{array}{ll}\text { T. M. Johnstone ; Nasīb and Mansöngur } & 90\end{array}$

H. al-Khateeb ; A Modern Syrian Short Story : Wajh al-qamar 96 
M. Moosa ; Naqqāsh and the Rise of the Native Arab Theatre in Syria 106 Modern Arabic Poetry, trans. Adel Salama, Zvi Gabay, Fouad Megally 118

'The Journey' by Yusuf Idris, trans. R. Alleen 127

Z. N. Abdel-Malek; The Influence of Diglossia on the Novels of Yuusif $\begin{array}{ll}\text { al-Sibaa'i } & 132\end{array}$

F. Klein-Franke; The Ḥamāsa of Abū Tammām (Part 2) 142 [vol. IV (1973)]

L. Abou-Saif ; Najīb al-R̄̄hān̄ī : From Buffoonery to Social Comedy 1

B. Connelly; The Structure of Four Bani Hilāl Tales 18

H. Kilpatrick; Hawwā' bilā Ādam: An Egyptian Novel of the 1930's 48 al-Ma'arrī : "Peace on earth ?" 57

I. J. Boullata; The Beleaguered Unicorn: A Study of Tawfīq Șāyigh 69

A. F. L. Beeston; Ships in a Quranic Simile 94

K. Dalgleish; Some Aspects of the Treatment of Emotion in the Diwān of $\begin{array}{ll}\text { al-A'shä } & 97\end{array}$

M. M. Badawi ; al-Māzin̄̄ the Novelist 112

'Antar and Juliette' by Yaḥyā Ḥaqqī, trans. P. Cachia 146 Review

History of Modern Arabic Literature, by A. I. Krimskiy (J. M. Landou) 157

$\begin{array}{lr}\text { Recent Publications } & 161\end{array}$

$\begin{array}{ll}\text { Note } & 164\end{array}$

いずれもが力作どろいで，地味ながら懇切丁寧な編集態度が感じられる。本誌 はアラブ文学の翻訳にもかなりのスペースを割いており，そのほとんどが戦後文 学の翻訳として際立っている。また, 論文も現代文学を扱っていることが多い。 発刊の辞 Introduction で編者たちは「アラブ文学が他の世界にもその影響を与え ていくとしたら，アラブ人と非アラブ人との間に和ける持続的な努力が必要で ある。その作品が提示され，評釈され，批評され，そしてそれらの背景や慣習が 分析され, 解説されていなければならない......われわれのアプローチは必ずや 〈民衆化>popularisation に対する何らかの試みが含まれていなければならない。 そして願わくば, アラビア語専攻の学生の要求に答えるのみならず，できるなら ば，比較文学の問題にかかわっている非アラビストの関心をもそそるものであり 
オリエントXVIII-1 (1975)

(3)

たい」(傍点筆者) と述べている。ここに本書の発刊されている意図もあるとい えよう。編者たちは，ここで基本的にはいわゆるくェクスプリカション・ド・テ キスト>に立脚することを宣言しているのだ。そして「われわれの主な課題は, 文学鑑賞の試論 Essay が刊行されることである……れわれはアラブ文学の翻 訳をも組み入れる計画がある……として将来は，アラブ文学の新刊案内を公表し (5)

たい」といって，本誌を基礎にした多面的な活動を約束している。

執筆者をみてみると，編者たちを中心に，現在西欧のアラブ文学研究の第一戦 で活躍している研究者はもらろんのこと, ジャブラ・イブラヒーム・ジャブラ (vol. 2) やカマール・アブー・ディーブ（vol. 2) などのように, 現在アラブ圈 で活躍している作家，文芸評論家，学者が寄稿しているが，それる以上の主旨か ら当然のこととい方よう。また，西欧のアラブ文学研究に多大なる貢献をなして きた故アーベリー教授の業績を記念して，第 2 巻よりくアーベリー記念賞 $>$ Arberry Memorial Prize (£ 50) を設立, 䀣賞論文を募集している。

発刊の辞で予告していたように，本誌の別冊のシリーズ書が企画され，すでに 出版を開始しているし，本誌に発表された翻訳を基礎に，最近単行本が刊行され ている。

そして西欧に扣けるアラブ文学の研究史を顧みるとき，本誌発刊のこうした意 図がいかに画期的なことか，すぐさま理解できるのだ。かつて故グルーネバウム Gustave E. von Grunebaum 博士は，西欧に括けるアラブ文学研究史に触れ，「世 界的な詩をもつどの国民文学にも信念を燃やすロマン主義と個一文化の概念の支 配を検討した新人文主義こそ，アラブ文学の研究を主に精神的に指導してくれた ものであることは, 明らかにされてきたことである」と述べ, 次のよらに批判し ている。まず西欧に拈けるアラブ文学研究は, ハンマー・プルグシュタール Joseph von Hammer Purgstall の『アラブ文学史』Literaturgeschichte der Araber, Wien，1850～56 が代表的なよらに，詳細だが十分に内容が検討されてはいない 研究から始屯った。そしてその反動として，アールヴァルトW. Ahlwardt のよ うな厳密なテキストニクリティークに基礎をおく研究者が出てきたと述懐する。 それらは確かに「現代の科学的な方法にらさわしい体系に先行しなければならな かったもの」としつつ, 博士はアラブ文学の新しい方法を考察しているのだ。

もちろん，本誌の編者たちの方法は故グルーネバウム博士のそれとは異なるも

のだが，また，博士が提起した西欧のアラブ文学研究法の欠点とその批判から生 
まれたのは，事実といえよう。

一部の研究者にとどまらず，広く関心ある層にもアラブ文学を普及させようと すれば, 当然翻訳を行なら傍ら, 今日的視点が求められてくる。現代アラブ文学 と西欧, 現代アラブ文学における伝統, 現代アラブ文学の新手法, 現代アラブの

文学運動, 文学作品の構造分析などが相互関係をもって主なテーマとされる由で ある。また，狭義の文学者ではなく，広く芸術家一般を論じているのも一つの特 徵だ。古典文学を扱う場合にも, 現代的方法が駆使されているのにも注目してい いだろら。

本誌は，こうした新しいアラブ文学研究法にのっとって，一つ一つが論及され ていくに足る論文で満たされている。書評が今まで 2 回 (第 2 巻と第 4 巻) しか 掲載されなかったのは，この種の研究誌にあってはすことに残念であるが，全体 的にみて, 新しい問題を提起しているのは否定できず，今後の日本に括けるア ブ文学研究法に対して多大な示唆を与えてくれることと思う。第 4 巻から設けら れているく新刊紹介> Recent Publications の闌は，ともすれば西欧・アラブ圈 の研究, 文学作品の現状に疎遠になりがちな日本の研究者にも, 計り知れない貢 献をしてくれるだろら。

ネルデケ Th. Nöldeke やブロッケルマンC. Brockelmann によって文献的研究 が確立した西欧のアラブ文学研究は，アーベリーA.J. Arberry によって文学鑑 賞の域に達し，歴史，思想史の補佐役に別れを告げた。

そして今や，本誌を軸に文学を一つの時代の証言として，刷新なる方法論を駆 使して，〈鑑賞〉 appréciation ではなく<分析〉 explication が試みられている。 〈相互理解>ではなく<相互交流>の研究が比較文学の観点から強調されている のは, アラブ圏のそれとともに, 今後の問題と可能性を数多く提起しているとい らべきなのだ。

\section{註}

1）拙稿「文献案内」，野間宏責任編集『現代アラブ文学選』創樹社, 1974,431頁, 同「『立場』誌の発刊をめぐって」, 『文芸展望』第 7 巻, 1974年, 448頁, 同 「図書紹介・Journal of Arabic Literature」,『日本比較文学会会報』第82号, 1975年， 7 頁に扣いて，筆者はすでに本誌の簡単な紹介を行なっている。 2) その後も多くの現代アラブ文学についての研究書などが刊行されているとは い光（註1）「文献案内」参照）「東方の文学の数あるなかで，アラビア語を用 
いている民族の現代文学がヨーロッパではほとんど注目されていないのは不思 議なことである。多分それは, ある程度アラビア語の読める少数のヨーロッパ 人がイスラムとイスラム教徒の過去の豊かな遺産にのみ熱中していて現代に対 しては何の関心をも抱かず，おそらく好奇心すらもたないからであろら」(ハ ミルトン・ギブ著内記良一訳「近代アラブ文学の動向」,『イスラム文明史』み すず書房, 1968, 122頁, 訳語一部訂正) といら言葉を思い出せば, その意味も 自ずから理解できよう。

3) Journal of Arabic Literature (以下 J.A. L. と略), vol. I, 1970, p. 1.

4) フランス語 Explication de Textes, 英語 Interpretation. こうした文学研究の 方法はフランスのリュドレル G. de Rudler によって基礎が固められたが，と りわけレオ・スピッツァーによって展開された。cf. Leo Spitzer: A Method of Interpreting Literature, N. Y., 1949

5) J. A. L., vol. I, 1970, p. 2.

6) "Studies in Arabic Literature” シリーズの第 1 巻, Khoury, M. A. ; Poetry and the Making of Modern Egypt 1882 1922, Leiden, 1971 之 "The Arabic Translation Series of J.A. L.” シリーズの第 1 巻, Salāh 'Abd al-Sabūr, Semaan, Khalil I. tr. : Murder in Baghdad, Leiden, 1972の二著。

7) Khoury, M. A. \& Algar, M. ; An Anthology of Modern Arabic Poetry, Los Angeles, 1974. 本書は今はなき, アラブの詩人にしてバークレー（カルフォル ニア大学）でアラブ文学と比較文学を講じていたタウフィーク・サーエグ Tawfīq Ṣāyigh に捧げられている。本書の二人の編者ももちろん, 現在バーク レーでアラブ文学を講じている。本書はジブラーシ Jibrān Khalīl Jibrān から ダルウィーシュ Maḥmūd Darwīsh に至る35詩人の79の詩をアラビア語原詩を そ光て訳出している。巻頭には現代アラブ詩史が解説され, 巻末に詩人紹介, 参考文献が付されている。

また，バダウィ M. M. Badawi 教授も本誌に現代アラブ詩を訳出しているが 第 1 巻, 第 2 巻), これは先に同教授が刊行したアラビア語によるアンソロジ - An Anthology of Modern Arabic Verse, Beirut/London, 1969 によってい る。

8) von Grunebaum, G. E. ; Kritik und Dichtkunst, Wiesbaden, 1955, p. 7.

9) Ibid., p. 7 参照。

10）Ibid., p.8 参照。現在，西欧ならびにアラブ圈のリプリント出版をみてみる と意外なほど彼ら (Ahlwardt, W., Nöldeke, Th., de Goeje, M. J. 等) の校訂本 が含まれている。こうした過去の地道な基礎の上に, 新しい方法を模索してい ることを忘れるべきではない。

11) Ibid., p. 7 .

12）例えば，博士は「われわれの研究を内面的に掘り下げようとする論理は，少 なくともより広い歩みが見い出せる。つまり, 文学作品と思想史の体系的並置 
だ」（Ibid., p. 16）と述べて，イスラム史のなかでアラブ文学を位置づけよう としている。同博士は，その意図を“The Aesthetic Foundation of Arabic Literature", Comparative Literature, IV, 1952, で試みている。

13）翻訳によってその国の文学を知ろうとするのも一つの手段である。本誌は, 前述のようにとりわけ比較文学の学徒に開放されているが, アメリカの比較文 学研究がく翻訳〉によって世界文学に接近しようとしているのは, 著名な事実 である。亀井俊介編『現代比較文学の展望』研究社, 1972，214〜 5頁参照。

14）多くの一般の関心ある人は, 過去はどうであったよりも, 文学研究ではタブ 一とされてきた現在どらであるかの方に関心をるつのは当然とい充よう。

15）恐らく比較文学の観点からのためと思う。Landau, Jacob M.(vol. I), Badawi, M. M. (vol. I), Jabra Ibrahim Jabra (vol. II), Cachia, P. (vol. II), AbdelHai, M. (vol. III) などはそういった興味ある論文である。

16) Badawi, M. M. (vol. II), Abdel-Malek, Z.N. (vol. III) などの論文。この極 めて重要にして関心をそそるテーマがいささかも論じられないのは，まことに 残念であり，片手落ちといわざるを得まい。

17) Somekh, S. (vol. I), Boullata, I. J. (vol. II), Ostle, R. C. (vol. II), Semah, D. (vol. II), Badawi, M. M. (vol. IV) などの論文のように，力作が多い。

18) al-Zubaidi (vol. I), Khouri, M. K. (vol. I), Moosa, M. (vol. III), Kilpatrick, H. (vol. IV) などの論文。al-Zubaidi 氏のアポロ運動期の詩人，作家の意識構 造の分析は注目してよい。

19) Lyons, M. C. \& Cachia, P. (vol. I), Roger Allen (vol. I), al-Hilāl (vol. II), Boullata, I. J. (vol. IV) などの論文。

20) Juynboll, G. H. A. (vol. III), Johnstone, T. M. (vol. III), Abou Saif, L. (vol. IV) なぞの論文。かつてフランスのすぐれた比較文学者ポール・アザー ル Paul Hasard は文学を育てる諸要素を重視し, それをL L C rise de la Con. science europeénne, Paris, 1935 で実践した。こうした総合的な文化・文化史 研究を志向する論考が多いのも, 本誌の特徴といえよう。

21）拙稿「新段階の『アラブ』文学」, 東京新聞, 1974年 9 月 4 日夕刊参照。例 えば，本誌の第二号でジュルジャーニー al-Jurjānī の言語・文学理論を検討し ているカマール・アブー・ディーブは『立場』Mawāqif 誌の第22号に掲載し

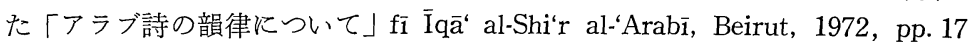
〜67といら論文でも, ハリール al-Khalīl b. Aḥmad の韻律学を現代構造主義 でもって批判, 新しい古典アラブ詩の構造分析を試みている。本誌がアラブ圏 の活動とも密接な関係をもっているのも, 極めて重要なことである。

22）筆者自身の方法については，拙稿『『ッ・スッカリーヤ』の一章をめぐっ て——日本に怙ける アラブ文学の可能性」, 『A A L A』第 6 巻, 1974, 拙著 『地中海の月と光・アラブ文学の波紋』カルチャー出版, 1975 (10月刊予定), 序章参照。 
オリエントXVIII-1 (1975)

23）アラブ圏に掠ける比較文学研究については, 拙稿「書評・al-Hilāl : $a l$-Adab al-Muqārin」，『比較文学』第十七巻，1974年参照。

付記

本稿のゲラ校正中に，本誌の第 5 巻 (1974) が送付された。これによると，同 年よりくアーベリー記念賞〉は£100に増額された。また，註6）で触れた“The Arabic Translation Series of J.A.L" の第 2 巻 Yaḥyā Haqqī, Badawi, M. M. tr. ; The Saint's Lamp and Other Stories, Leiden. 1973 が刊行された。

な抒，第 5 巻の総目次は下記のと抒り。

[vol. V (1974)] page

Jareer Abu-Haidar; Maqãmāt Literature and the Picaresque Novel

T. J. Gorton; Arabic Influence on the Troubadours : Documents and Directions 11

A. M. K. Zubaidi ; The Apollo School's Early Experiments in "Free Verse" 17

C. Knipp; The Arabian Nights in England: Galland's Translation and its Successors

N. Naimy ; The Mind and Thought of Khalil Gibran 55

D. C. Cowell ; Ibn 'Abd Rabbihi and his Ghazal Verse 72

H. Nemah; Andalusian Maqāmāt 83

H. Kilpatrick; The Arabic Novel-a single tradition? 93

'A God in spite of himself' by Fatḥ̄ Raḍwān, trans. P. Cachia 108

Two Kuwaiti Poems, by Ahmad Adwani. trans. Adel Salama 127

Two Palestinian Poems, by Mu'ine Bessissou and Mahmoud Darweesh, $\begin{array}{ll}\text { trans. Badreddine M. Bennani } & 129\end{array}$

A. F. L. Beeston; Parallelism in Arabic Prose 134

Mona N. Mikhail; Broken Idols, the Death of Religion in Two Stories by $\begin{array}{ll}\text { Idrīs and Maḥfūz } & 147\end{array}$

Recent Publications 158

以上のように，発刊の辞で述べた理想が一歩一歩前進しつつあるといえる。ま た，本稿で筆者が指摘した本誌のく意味〉もますます濃厚になってきているとい える。 